Article

\title{
Microwave Synthesis, Basic Spectral and Biological Evaluation of Some Copper (II) Mesoporphyrinic Complexes
}

\section{Rica Boscencu $^{1, *}$, Mihaela Ilie ${ }^{1, *}$, Radu Socoteanu ${ }^{2}$, Anabela Sousa Oliveira ${ }^{3,4}$, Carolina Constantin ${ }^{5}$, Monica Neagu ${ }^{5}$, Gina Manda ${ }^{5}$ and Luis Filipe Vieira Ferreira ${ }^{3}$}

1 Faculty of Pharmacy, "Carol Davila” University of Medicine and Pharmacy, 6 Traian Vuia St., 020956 Bucharest, Romania

2 "Ilie Murgulescu" Institute of Physical Chemistry, Romanian Academy, 202 Splaiul Independenţei, 060021 Bucharest, Romania; E-Mail: psradu@yahoo.com (R.S.)

3 Centro de Química-Física Molecular, Institute of Nanosciences and Nanotechnology, Instituto Superior Técnico Av. Rovisco Pais 1049-001, Lisbon, Portugal;

E-Mails: asoliveira@estgp.pt (A.S.O.); luisfilipevf@ist.utl.pt (L.F.V.F)

4 Escola Superior de Tecnologia e Gestão de Portalegre, Instituto Politécnico de Portalegre, Apartado 148, 7300-901 Portalegre, Portugal

5 "Victor Babeş" National Institute for Pathology and Biomedical Sciences, Bucharest, 99-101 Splaiul Independenței, 050096 Bucharest, Romania; E-Mail: caroconstantin@yahoo.com (C.C.)

* Authors to whom correspondence should be addressed; E-Mails: rboscencu@yahoo.com (R.B.); m16ilie@yahoo.com (M.I.); Tel.: +4021-3111152; Fax: +4021-3111152.

Received: 27 April 2010; in revised form: 19 May 2010 / Accepted: 24 May 2010 /

Published: 25 May 2010

Abstract: $\mathrm{Cu}(\mathrm{II})$ complexes with asymmetrical and symmetrical porphyrinic ligands were synthesized with superior yields using microwave irradiation. The paper presents the synthesis of 5-(3-hydroxyphenyl)-10,15,20-tris-(4-carboxymethylphenyl)-21,23-Cu(II)porphine in comparison to its symmetrical complex 5,10,15,20-meso-tetrakis-(4-carboxymethylphenyl)-21,23-Cu(II) porphine. The two compounds were characterized by FT-IR, UV-Vis and EPR spectroscopy, which fully confirmed the structures. The spectral molecular absorption properties of the porphyrinic complexes were studied in organic solvents (methanol, ethanol, iso-propanol, dimethyl sulfoxide, dimethylformamide and methylene chloride), and the influence of the solvent polarity on the absorbance maxima is described. In order to establish their future potential in biomedical applications preliminary toxicological studies consisting of viability and proliferation of standard tumor cell lines 
(MCF7 and B16) testing was performed. The obtained results indicate a low toxicity for both compounds and further recommends them for testing in light activation protocols.

Keywords: copper (II) mesoporphyrinic complexes; FT-IR spectroscopy; solvatochromy; cytotoxicity

\section{Introduction}

Porphyrins and metalloporphyrins represent one of the most widely studied of all known macrocyclic ring systems [1]. The synthesis of metalloporphyrins and the investigation of their chemical and biological properties has attracted increased interest in both bioinorganic chemistry and medical chemistry, mainly due to their possible use in unconventional treatment of various diseases by means of photodynamic therapy (PDT) [2], which is a selective method of treatment of several diseases, amongst which the most cited are cancer and psoriasis. The technique involves the administration of a pharmaceutical formulation containing a specific photosensitizer, its selective localization at the level of the sick cells, laser irradiation of the photosensitizer-loaded tissue, followed by the generation of a very reactive chemical species, the singlet oxygen $\left({ }^{1} \mathrm{O}_{2}\right)$, that destroys the cells [3-9]. The most important advantage of photodynamic therapy consists in the use of visible light range, having much lower energies compared to those used in the classical radiological therapy.

The first porphyrins used in the PDT were the hematoporphyrin derivatives (HPD). A purified HPD fraction (the sodium porphymer) represents the active component of the pharmaceutical formulation PHOTOFRIN $^{\circledR}$, used in the treatment of esophageal cancer. The results obtained using PHOTOFRIN ${ }^{\circledR}$ in PDT proved that it presented a series of disadvantages as follows: its composition included several inactive PDT derivatives; it was slowly eliminated from healthy tissues so patients remained photosensitive to the solar radiation, in certain cases more than a month after the procedure. However, the greatest disadvantage of PHOTOFRIN ${ }^{\circledR}$ is connected to its spectral properties, its strongest light absorption band being situated in a rather inefficient spectral range for PDT [2,10-12].

A second generation of photosensitizers includes porphyrinic structures as tetra-( $m$-hydroxyphenyl) chlorine or $m$-THPC, the active substance of the pharmaceutical formulation FOSCAN ${ }^{\circledR}$, used in the treatment of head and neck cancers. The doses for an individual administration are rather low compared to PHOTOFRIN $^{\circledR}(0.1 \mathrm{mg} / \mathrm{kg}$ body weight $)$ and the irradiation wavelength is at $\lambda=652 \mathrm{~nm}[13]$.

Recently, research has been directed towards obtaining new photosensitizers that meet the following requirements: a high purity and simple production under laboratory conditions; photoactivity at wavelengths higher than 630-680 nm; acceptable solubility in biologic fluids for an easy localization at the cellular and subcellular level; great selectivity for the malignant or other targeted tissue; lack of toxicity in the absence of the exciting light; rapid elimination from the body after the treatment is performed and non-toxic metabolites [14-22].

This paper presents the characteristics of a newly synthesized asymmetrical $\mathrm{Cu}$ (II) porphyrinic complex, namely 5-(3-hydroxyphenyl)-10,15,20-tris-(4-carboxymethylphenyl)-21,23 Cu(II) porphine (denoted as $\mathrm{Cu}(\mathrm{II}) \mathrm{TCMPOH}_{\mathrm{m}}$ - Figure 1) and a comparison to the corresponding symmetrical 
compound - 5,10,15,20-meso-tetrakis-(4-carboxymethylphenyl)-21,23-Cu(II) porphine (denoted as $\mathrm{Cu}$ (II)TCMP - Figure 1), obtained using microwave irradiation, aiming at further investigation of the theoretical and preclinical aspects of their possible use in PDT.

Figure 1. Structures of 5-(3-hydroxyphenyl)-10,15,20-tris-(4-carboxymethylphenyl)-21, $23 \mathrm{Cu}$ (II) porphine $\left(\mathrm{Cu}\right.$ (II) $\left.\mathrm{TCMOH}_{\mathrm{m}}\right)$ (top) and 5,10,15,20-meso-tetrakis-(4-carboxymethylphenyl)-21,23-Cu(II) porphine (Cu(II)TCMP) (bottom).

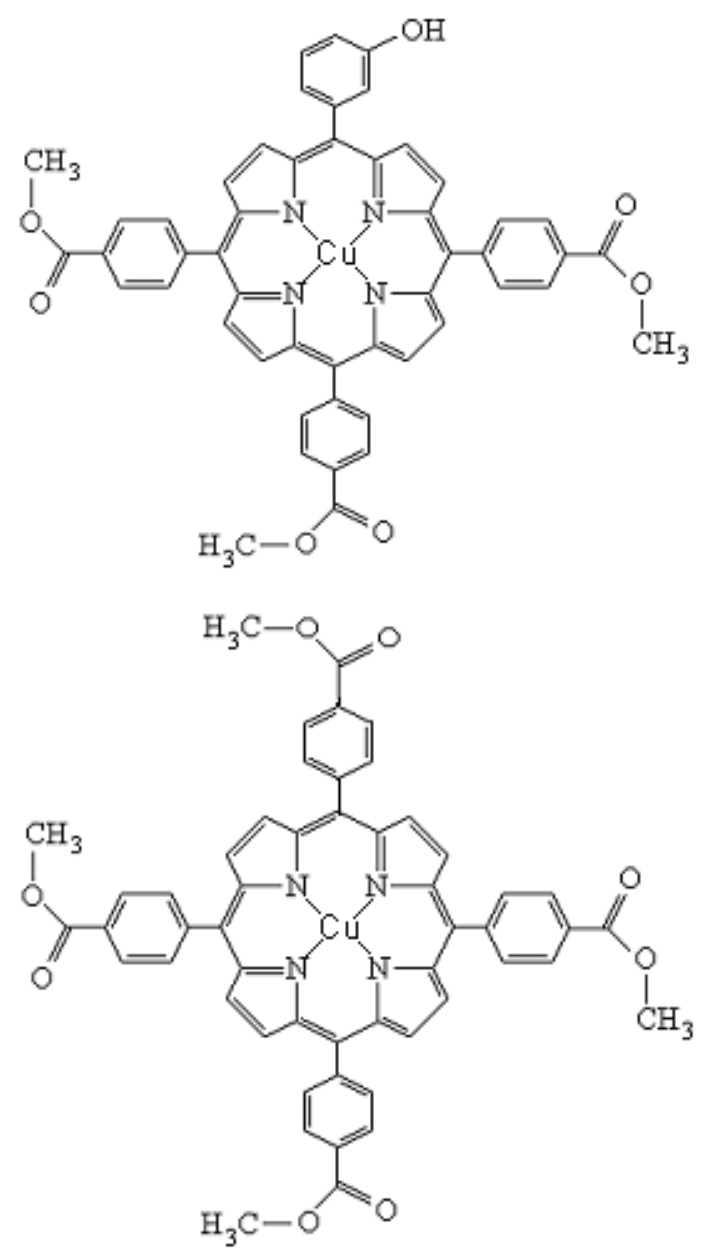

\section{Results and Discussion}

\subsection{Infrared spectra}

The important band frequencies of the ligand and copper complexes and corresponding assignments are presented in Table 1. The IR spectra of the porphyrinic ligands $\mathrm{TCMPOH}_{\mathrm{m}}$ and TCMP were analyzed in a previous paper [23]. The IR bands of the ligands at approx. $3,310 \mathrm{~cm}^{-1}$ and $963 \mathrm{~cm}^{-1}$ are due to the $\mathrm{N}-\mathrm{H}$ stretching and bending vibration of the porphyrinic core, but they disappear in the complexes because the hydrogen atom in the $\mathrm{N}-\mathrm{H}$ bonding is replaced by the $\mathrm{Cu}(\mathrm{II})$ ion. The bands at $3,503 \mathrm{~cm}^{-1}$ are assigned to $\mathrm{O}-\mathrm{H}$ stretching vibration of the $-\mathrm{OH}$ functional group in the $\mathrm{TCMPOH}_{\mathrm{m}}$ and $\mathrm{Cu}(\mathrm{II}) \mathrm{TCMPOH}_{\mathrm{m}}$. Other bands observed in the higher wavenumber region $\left(2,957-2,923 \mathrm{~cm}^{-1}\right)$ are due to the stretching vibration of $\mathrm{C}-\mathrm{H}$ bond of the porphyrinic ring. The bands of the compounds in the range of $1,715-1,720 \mathrm{~cm}^{-1}$ are assigned to $\mathrm{C}=\mathrm{O}$ stretching vibrations. The IR spectrum of the free-base 
porphyrins and $\mathrm{Cu}(\mathrm{II})$ complexes clearly indicates the presence of the $-\mathrm{O}-\mathrm{CH}_{3}$ group in the spectral range $2,848-2,853 \mathrm{~cm}^{-1}$.

Table 1. Characteristic IR vibrations of the free base porphyrins and their $\mathrm{Cu}(\mathrm{II})$ complexes (KBr pellet).

\begin{tabular}{|c|c|c|c|c|}
\hline \multirow{2}{*}{ Characteristic vibration } & \multicolumn{4}{|c|}{ Wavenumber of the IR band $\left(\mathrm{cm}^{-1}\right)$} \\
\hline & TCMP $^{1}$ & Cu(II)TCMP & TCMPOH $_{m}{ }^{1}$ & Cu(II) TCMPOH \\
\hline$v_{\mathrm{O}-\mathrm{H}}$ & - & - & $3503 m$ & $3493 m$ \\
\hline$v_{\mathrm{N}-\mathrm{H}}$ & $3310 w$ & - & $3312 m$ & - \\
\hline$v_{\mathrm{C}-\mathrm{H}}$ & $2950 m$ & $2954 m$ & $2952 m$ & $2957 m$ \\
\hline$v_{\mathrm{C}-\mathrm{H}}$ & $2923 m$ & $2924 m$ & $2923 v . s$ & $2923 m$ \\
\hline$v_{\mathrm{C}-\mathrm{H}}$ from $-\mathrm{O}-\mathrm{CH}_{3}$ & $2851 s$ & $2853 s$ & $2853 m$ & $2848 s$ \\
\hline$v_{\mathrm{C}=\mathrm{O}}$ & 1717 v.s. & $1715 s$ & $1718 s$ & $1720 m$ \\
\hline$v_{\mathrm{C}-\mathrm{N}}$ & $1603 m$ & $1604 m$ & $1597 s$ & $1600 s$ \\
\hline$v_{\mathrm{C}-\mathrm{H}}$ pyrrole & $1400 m$ & $1402 w$ & $1401 \mathrm{~m}$ & $1410 w$ \\
\hline$v_{\mathrm{C}-\mathrm{O}}$ & $1156 s$ & $1164 m$ & $1156 s$ & $1164 m$ \\
\hline$\delta_{\mathrm{C}-\mathrm{H}}$ & $1018 m$ & $1014 m$ & $1020 w$ & $1010 w$ \\
\hline$\delta_{\mathrm{N}-\mathrm{H}}$ pyrrole & $963 m$ & - & $964 m$ & - \\
\hline$\gamma_{\mathrm{C}-\mathrm{C}}$ & & $869 w$ & $858 w$ & $862 w$ \\
\hline$\gamma_{\mathrm{C}-\mathrm{N}}$ pyrrole & $798 m$ & $797 s$ & $790 m$ & $795 s$ \\
\hline
\end{tabular}

The intensities of the signals are described as weak $(w)$, medium $(m)$, strong $(s)$ and very strong (v.s.); ${ }^{1}$ Data for this compound were taken from [23].

\subsection{Molecular electronic spectra}

Molecular electronic spectra were studied for the free-base porphyrins, $\mathrm{Cu}(\mathrm{II}) \mathrm{TCMP}$ and $\mathrm{Cu}(\mathrm{II}) \mathrm{TCMPOH}_{\mathrm{m}}$ in different solvents (methanol - $\mathrm{MeOH}$, ethanol - EtOH, isopropanol - iso-PrOH, dimethylsulfoxide - DMSO, dimethylformamide - DMF, dichloromethane - $\mathrm{CH}_{2} \mathrm{Cl}_{2}$ ). For this purpose, porphyrin solutions were freshly prepared in spectrally pure solvents at a concentration of $2.5 \times 10^{-6} \mathrm{M}$. Solutions were kept in dark to prevent photodegradation. All the absorption spectra were recorded for the same samples. The obtained results are presented in Figures 2 and 3 and Table 2.

Figure 2. Absorption spectra of $2.5 \times 10^{-6} \mathrm{M} \mathrm{Cu}(\mathrm{II}) \mathrm{TCMP}$ in different solvents (a-Soret band; $\mathbf{b}-\mathrm{Q}$ bands).

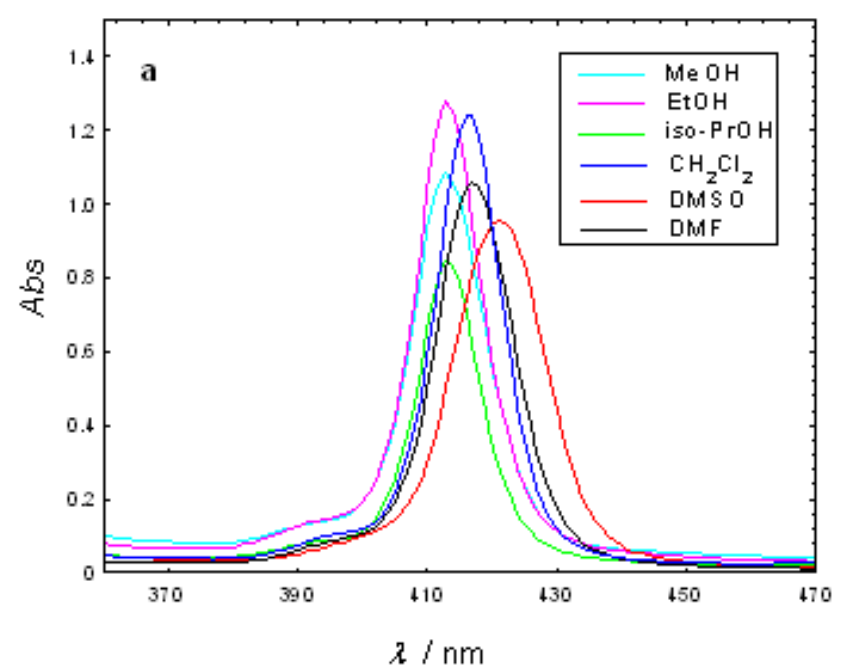


Figure 2. Cont.

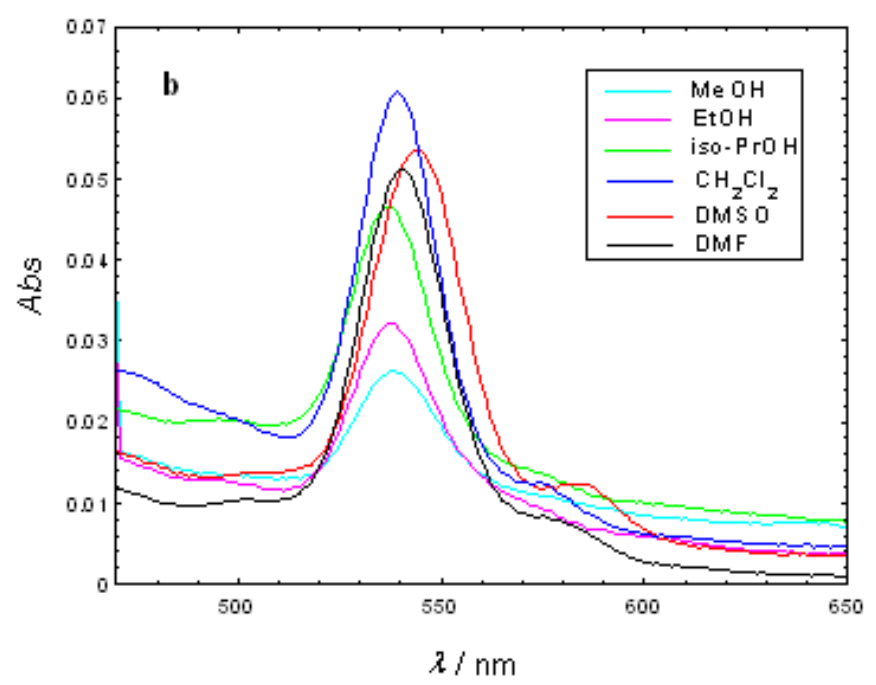

Figure 3. Absorption spectra of $2.5 \times 10^{-6} \mathrm{M} \mathrm{Cu}(\mathrm{II}) \mathrm{TCMPOH}_{\mathrm{m}}$ in different solvents (aSoret band; b-Q bands).
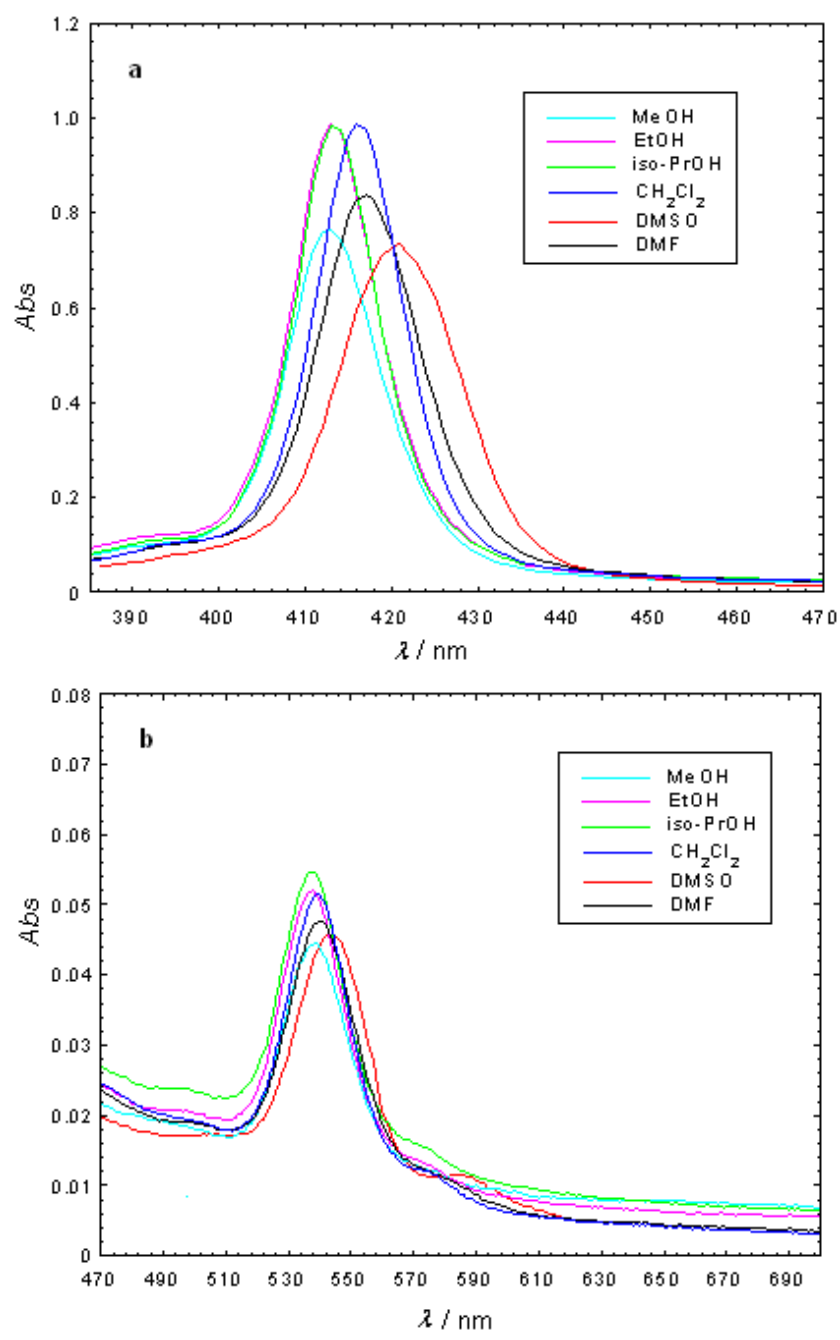
Table 2. Maximum wavelength and molar absorptivity of the porphyrinic ligands, $\mathrm{Cu}(\mathrm{II}) \mathrm{TCMP}$ and $\mathrm{Cu}(\mathrm{II}) \mathrm{TCMPOH}_{\mathrm{m}}$ in different solvents $\left(\mathrm{c}=2.5 \times 10^{-6} \mathrm{M}\right)$.

\begin{tabular}{|c|c|c|c|c|c|}
\hline \multirow{2}{*}{ Solvent } & \multicolumn{5}{|c|}{$\lambda_{\max }(\mathrm{nm})\left[\lg \varepsilon\left(\mathrm{L} \mathrm{mol}^{-1} \mathrm{~cm}^{-1}\right)\right]$} \\
\hline & Soret $\mathbf{B}(\mathbf{0 , 0})$ & $Q_{y}(\mathbf{1}, \mathbf{0})$ & $Q_{y}(\mathbf{0 , 0})$ & $Q_{x}(\mathbf{1}, \mathbf{0})$ & $\mathbf{Q}_{\mathbf{x}}(\mathbf{0 , 0})$ \\
\hline \multicolumn{6}{|c|}{ 5, 10, 15, 20-meso-tetrakis-(4-carboxymethylphenyl) - 21,23-H porphine } \\
\hline $\mathrm{MeOH}$ & $415.3[5.528]$ & $514.8[4.415]$ & $544.3[4.387]$ & $591.9[4.265]$ & $646.9[4.342]$ \\
\hline $\mathrm{EtOH}$ & $416.4[5.546]$ & $512.5[4.428]$ & $547.4[4.283]$ & $590.4[4.225]$ & $647.4[4.146]$ \\
\hline iso-PrOH & $416.8[5.511]$ & $513.5[4.301]$ & $546.9[4.049]$ & $592.4[3.857]$ & $648.4[3.602]$ \\
\hline $\mathrm{CH}_{2} \mathrm{Cl}_{2}$ & $419.6[5.699]$ & $515.2[4.344]$ & $550.0[4.000]$ & $590.1[3.806]$ & $645.5[3.643]$ \\
\hline DMSO & $420.9[5.602]$ & $515.6[4.310]$ & $550.0[4.049]$ & $590.1[4.000]$ & $645.6[3.833]$ \\
\hline DMF & $419.3[5.662]$ & $514.3[4.326]$ & $548.7[4.017]$ & $589.6[3.833]$ & $645.3[3.716]$ \\
\hline \multicolumn{6}{|c|}{ 5, 10 ,15,20-meso-tetrakis-(4-carboxymethylphenyl)-21,23-Cu(II)porphine } \\
\hline $\mathrm{MeOH}$ & $412.5[5.637]$ & - & $538.2[4.024]$ & - & - \\
\hline $\mathrm{EtOH}$ & $413.0[5.709]$ & - & 537.7 [4.107] & - & - \\
\hline iso-PrOH & $413.1[5.527]$ & - & $537.0[4.274]$ & $574.8(\mathrm{sh})$ & - \\
\hline $\mathrm{CH}_{2} \mathrm{Cl}_{2}$ & 416.4 [5.697] & - & 539.4 [4.387] & $574.5(\mathrm{sh})$ & - \\
\hline DMSO & $421.6[5.582]$ & - & $544.1[4.334]$ & $584.6[3.681]$ & - \\
\hline DMF & $417.0[5.627]$ & - & $540.3[4.310]$ & $578.0(\mathrm{sh})$ & - \\
\hline \multicolumn{6}{|c|}{ 5- (3-hydroxyphenyl)-10, 15, 20-tris-(4-carboxymethylphenyl) - 21,23-H porphine } \\
\hline $\mathrm{MeOH}$ & $422.4[5.582]$ & $513.1[4.158]$ & $554.8[4.193]$ & $595.5[3.924]$ & $647.6[3.643]$ \\
\hline $\mathrm{EtOH}$ & $424.1[5.561]$ & $513.4[4.134]$ & $556.3[4.158]$ & $596.1[3.857]$ & $649.4[3.556]$ \\
\hline iso-PrOH & $424.6[5.577]$ & $513.1[4.146]$ & $556.0[4.182]$ & $596.7[3.881$ & $650.3[3.602]$ \\
\hline $\mathrm{CH}_{2} \mathrm{Cl}_{2}$ & $420.1[5.607]$ & $515.2[4.121]$ & $548.8[4.146]$ & $588.9[3.716]$ & $647.9[3.556]$ \\
\hline DMSO & $429.3[5.546]$ & $516.1[4.170]$ & $558.6[4.182]$ & $598.8[3.944]$ & $648.8[3.681]$ \\
\hline DMF & 426.5 [5.519] & 514.9 [4.107] & $556.8[4.121]$ & 597.9 [3.833] & $648.2[3,556]$ \\
\hline \multicolumn{6}{|c|}{ 5-(3-hydroxyphenyl)-10, 15, 20-tris-(4-carboxymethylphenyl)-21,23- Cu(II)porphine } \\
\hline $\mathrm{MeOH}$ & $412.7[5.486]$ & - & $538.3[4.255]$ & - & - \\
\hline $\mathrm{EtOH}$ & 413.1 [5.598] & - & $537.1[4.318]$ & - & - \\
\hline iso-PrOH & $413.6[5.593]$ & - & $537.7[4.342]$ & $570.3(\mathrm{sh})$ & - \\
\hline $\mathrm{CH}_{2} \mathrm{Cl}_{2}$ & $416.1[5.598]$ & - & $539.5[4.310]$ & - & - \\
\hline DMSO & $421.0[5.468]$ & - & $544.0[4.265]$ & $585.9(\mathrm{sh})$ & - \\
\hline DMF & $417.0[5.525]$ & - & $540.0[4.283]$ & $579.6(\mathrm{sh})$ & - \\
\hline
\end{tabular}

sh - shoulder; $\mathrm{MeOH}=$ methanol, $\mathrm{EtOH}=$ ethanol, iso- $\mathrm{PrOH}=$ isopropyl alcohol, $\mathrm{DMSO}=$ dimethylsulfoxide, $\mathrm{DMF}=$ dimethylformamide, $\mathrm{CH}_{2} \mathrm{Cl}_{2}=$ dichloromethane.

The electronic absorption spectrum of the free-base porphyrins is dominated by a typical Soret band and four Q bands located in the spectral range 415-650 $\mathrm{nm}$, depending on the solvent [23]. The Q bands of the free base porphyrins consist of four absorption peaks which are typical to the $\mathrm{Qx}(0,0)$, $\mathrm{Qx}(0,1), \mathrm{Qy}(0,0), \mathrm{Qy}(0,1)$ transitions in the free base porphyrin $\left(\mathrm{D}_{2 \mathrm{~h}}\right.$ symmetry). After the metal ion entered into the body of the porphyrin, the number of $\mathrm{Q}$ bands decreases and the absorption frequencies shifts due to the increasing of the molecular symmetry from $D_{2 h}$ to $D_{4 h}$.

The UV-VIS spectra of the $\mathrm{Cu}(\mathrm{II}) \mathrm{TCMPOH}_{\mathrm{m}}$ and $\mathrm{Cu}(\mathrm{II}) \mathrm{TCMP}$ exhibited one Soret band in the spectral range of 412-421 nm accompanied by two Q bands, respectively in the 538-544 $\mathrm{nm}$ and 570-585 $\mathrm{nm}$ spectral range. Also, in the $\mathrm{Cu}(\mathrm{II}) \mathrm{TCMP}$ and $\mathrm{Cu}(\mathrm{II}) \mathrm{TCMPOH}_{\mathrm{m}}$ the $\mathrm{Q}$ bands are 
hypsochromically shifted and partially overlapped, as already reported in the literature for other metalloporphyrins of the same type [14,24-27].

It should be noticed that the wavelength of the Soret band maximum changes in the various solvents. As well, the relative intensities of the Soret band to the Q bands differ in some solvents. The Soret band of TCMP is shifted by about $3 \mathrm{~nm}$, whereas this shift is larger for $\mathrm{TCMPOH}_{\mathrm{m}}$, $\mathrm{Cu}(\mathrm{II}) \mathrm{TCMPOH}_{\mathrm{m}}$ and $\mathrm{Cu}(\mathrm{II}) \mathrm{TCMP}$ (about $9 \mathrm{~nm}$ ). That could be explained by the stronger interactions of the porphyrinic compounds with the solvent dipoles. The changes in Soret and Q bands can be associated with the solvent polarity [28] and the interactions between the porphyrinic substitutents and the solvent molecule.

The blue-shift of the bands with increasing polarity of the solvents should be noticed for porphyrinic ligands and their $\mathrm{Cu}$ (II) complexes. Thus, the absorption bands of the ligands and $\mathrm{Cu}(\mathrm{II})$ complexes in alcohol was blue-shifted which can be ascribed to the formation of proton bridges between the alcohol molecules and the porphyrinic compounds due to the polarity-induced and proton properties of the alcohol.

\subsection{EPR spectra}

EPR spectra of the newly synthesized complexes were recorded on powders at room temperature. It provides information about the environment of the $\mathrm{Cu}(\mathrm{II})$ within the porphyrinic ligand and the coordination geometry. The EPR spectrum of the synthesized complexes indicates the presence of the $\mathrm{Cu}(\mathrm{II})$ in tetrahedral surroundings with $\mathrm{D}_{4 \mathrm{~h}}$ symmetry.

The values of the magnetic parameters $g_{\|}, g_{\perp}, A_{\|}$and $A_{\perp}$ for $\mathrm{Cu}(\mathrm{II}) \mathrm{TCMPOH}$ and $\mathrm{Cu}(\mathrm{II}) \mathrm{TCMP}$ were calculated and are presented in Table 3. These magnetic parameter values, obtained from the EPR spectra of $\mathrm{Cu}(\mathrm{II})$ with the porphyrinic ligands are close to those reported in the literature [29,30]. Also, the $g_{\|}$value $\left(g_{\|}<2.3\right)$ indicates a covalent character of the $\mathrm{Cu}-\mathrm{N}$ bonds in the copper-porphyrinic complexes [31].

Table 3. Magnetic parameter values corresponding to $\mathrm{Cu}(\mathrm{II})$ complex combinations with porphyrinic ligands.

\begin{tabular}{|l|c|c|c|c|}
\hline Complex combination & $\boldsymbol{g}_{\|}$ & $\boldsymbol{g}_{\perp}$ & $\boldsymbol{A}_{\|} \mathbf{x} \mathbf{1 0}^{\mathbf{4}}\left(\mathbf{c m}^{-\mathbf{1}}\right)$ & $\boldsymbol{A}_{\perp} \mathbf{x} \mathbf{1 0}^{\mathbf{4}} \mathbf{( c m}^{-\mathbf{1}} \mathbf{)}$ \\
\hline $\mathrm{Cu}(\mathrm{II}) \mathrm{TPPOH}_{\mathrm{m}}{ }^{1}$ & 2.113 & 2.055 & 202 & 28 \\
$\mathrm{Cu}(\mathrm{II}) \mathrm{TCMP}$ & 2.162 & 2.042 & 203 & 32 \\
$\mathrm{Cu}(\mathrm{II}) \mathrm{TCMPOH}_{\mathrm{m}}$ & 2.170 & 2.045 & 201 & 33 \\
\hline
\end{tabular}

${ }^{1}$ Data for this compound were taken from [25].

\subsection{Preliminary toxicological tests}

As the foreseen application of the compounds will be PDT, we have used standard cell lines that originated from tumors like skin melanoma and breast cancer that can be treated by photodynamic therapy. Different incubation times were used in order to test the short and longer term effects on the cell physiology. For MCF7 line, after a short $2 \mathrm{~h}$ incubation no major effect was registered in the concentration ranges, but after $24 \mathrm{~h}$ at higher doses $(>50 \mu \mathrm{M})$, the LDH release was slightly enhanced while proliferation was reduced (Figure 4), mainly for $\mathrm{Cu}(\mathrm{II}) \mathrm{TCMPOH}_{\mathrm{m}}$. 
Figure 4. Cellular response of MCF7 line after $24 \mathrm{~h}$ incubation with $\mathrm{Cu}(\mathrm{II}) \mathrm{TCMPOH}$.

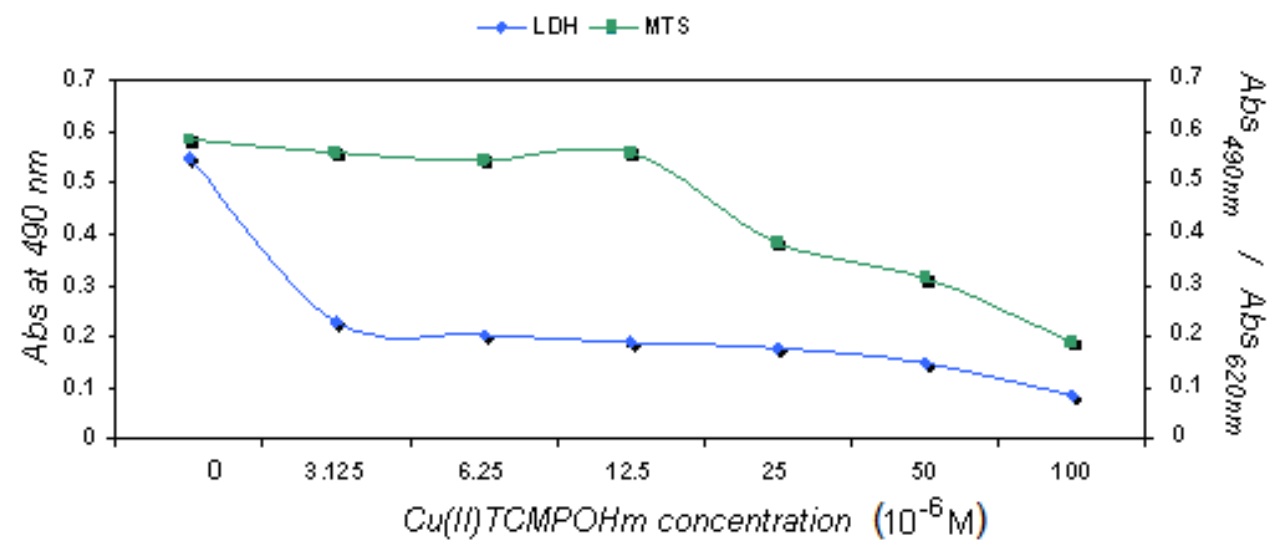

However at low doses of both copper complexes, the viability and proliferation were not related to the applied dose, results that support the low toxicity of both compounds. Regarding B16 skin melanoma standard cell line, the results were quite similar to those obtained for MCF7 line (Figure 5), namely after short periods of incubation no major effect is registered. After $24 \mathrm{~h}$ of incubation in low doses this cell line is as well not affected by the compounds. The lack of dark toxicity on a large concentration domain recommends these compounds for further testing in experimental approaches for activation upon light irradiation.

Figure 5. Cellular response of B16 line after $2 \mathrm{~h}$ incubation with $\mathrm{Cu}(\mathrm{II}) \mathrm{TCMPOH}_{\mathrm{m}}$ and $\mathrm{Cu}(\mathrm{II}) \mathrm{TCMP}$ (a - viability, $\mathbf{b}$ - proliferation).

a

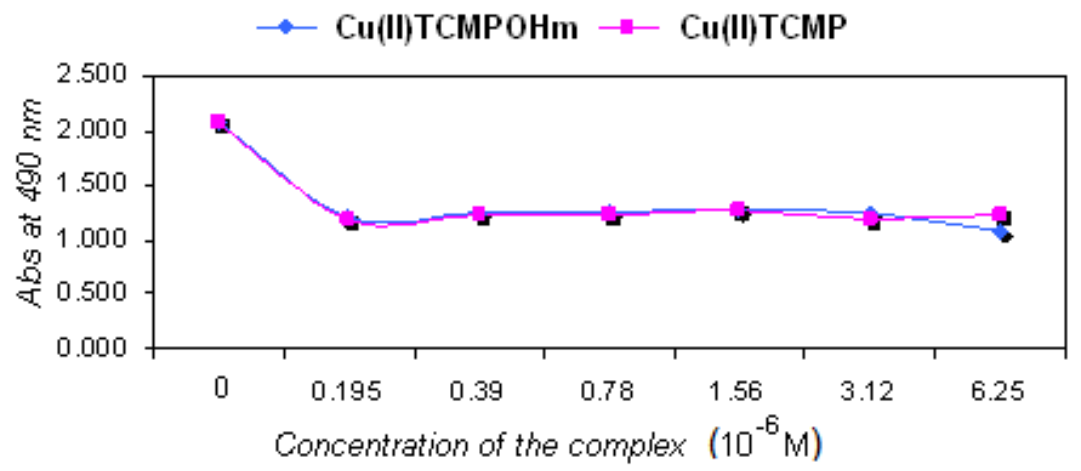

b

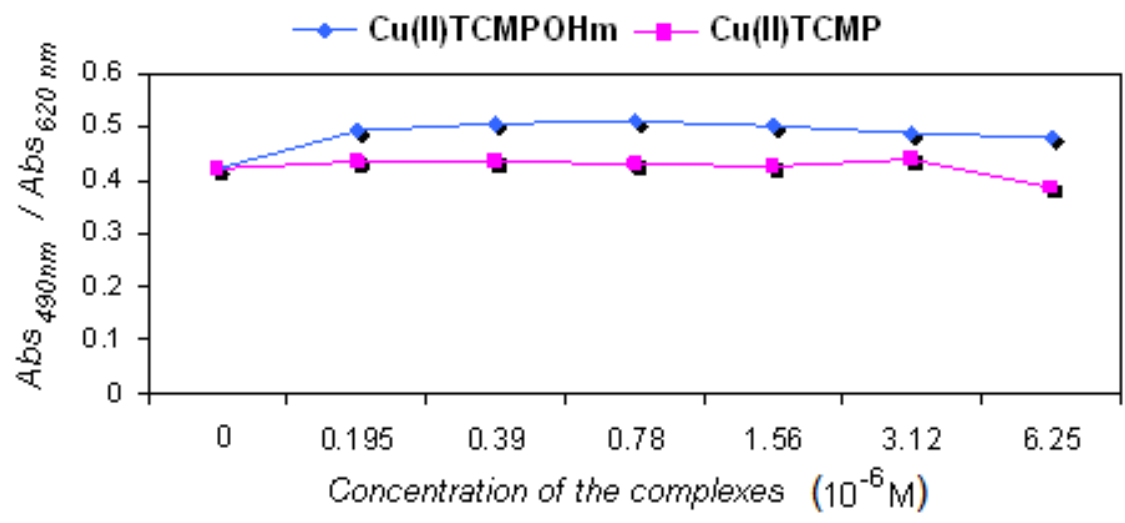




\section{Experimental}

\subsection{Materials and Methods}

Commercially available chemicals and solvents were used as received from Sigma-Aldrich and Merck. IR spectra were recorded with a FT-IR 400D Nicolet Impact spectrophotometer. The substances under analysis, previously dried for $24 \mathrm{~h}$ at $150{ }^{\circ} \mathrm{C}$, were processed as $\mathrm{KBr}$ (spectrally pure) pellets. The spectra were recorded in the $4,000-500 \mathrm{~cm}^{-1}$ spectral range.

The molecular absorption spectra were recorded on a Lambda 35 Perkin-Elmer spectrophotometer in solution, using a $10 \mathrm{~mm}$ path length quartz cell (Hellma), in single beam mode. UV-Visible spectra were obtained for $\mathrm{Cu}$ (II)TCMP and $\mathrm{Cu}(\mathrm{II}) \mathrm{TCMPOH}_{\mathrm{m}}$ in different solvents: $\mathrm{MeOH}$, EtOH, iso- $\mathrm{PrOH}$, DMSO, DMF, $\mathrm{CH}_{2} \mathrm{Cl}_{2}$. The porphyrin solutions were freshly prepared in the spectrally pure solvents at the concentration $2.5 \times 10^{-6} \mathrm{M}$. The solutions were kept in dark to prevent photodegradation.

EPR spectra of the newly synthesized complexes were recorded using a ART-6 spectrometer, operating in the $\mathrm{X}$ band $(9.01 \mathrm{GHz})$, equipped with a field modulation unit of $100 \mathrm{KHz}$. Mn(II) salt in $\mathrm{MgO}$ was used as a reference for the magnetic field calibration. The spectra were recorded on powders at room temperature.

For preliminary toxicological studies viability and proliferation in presence of copper porphyrinic complexes was performed on standard cell lines provided by the European Collection of Cell Cultures (ECACC) as following: MCF7 (human mammary adenocarcinoma cell line - ECACC 86012803) and B16 (murine cutaneous melanoma cell line - ECACC 94042254) cells. The compounds were used in sterile conditions after resuspension in DMSO followed by sonication at $22000 \mathrm{~Hz}$ for 30 seconds. The stock solutions were diluted in the appropriate culture medium for each cell line at the stated concentrations. The complexes were studied in two concentration ranges $(3.125-100 \mu \mathrm{M}$ and 0.195-6.26 $\mu \mathrm{M}$ ), following $2 \mathrm{~h}$. and $24 \mathrm{~h}$ incubation with the mentioned cell lines. For viability we have used lactate dehydrogenase (LDH) release test [32], with CytoTox $96^{\circledR}$ Non-Radioactive Cytotoxicity Test (Promega) and the cell proliferation by means of the tetrazolium salt (MTS) reduction test [33], using CellTiter $96^{\circledR} \mathrm{AQ}_{\text {eous }}$ One Solution Cell Proliferation Assay kit (from Promega). Results were expressed as triplicates mean of optical density (OD) at $490 \mathrm{~nm}$ for the mentioned viability and proliferation tests.

\subsection{Synthesis of copper porphyrinic complexes}

We have previously reported the synthesis of porphyrinic complexes from the corresponding tetrapyrrolic ligand and appropriate metal salts in the presence of a basic catalyst, 2,6-dimethylpyridine $[24,25]$. However, in recent years, synthesis via microwave irradiation has attracted considerable attention, as microwave-assisted reactions are believed to facilitate the polarization of the substrates thereby promoting the reactions [34-37]. Microwave-assisted reactions have become increasingly important in the synthesis of tetrapyrrolic compounds due to advantages such as significant reduction in reaction times and side reactions, increased yields, ease of purification and minimization of the amount of solvent used [38,39]. These are the reasons why in this paper the synthesis of the copper porphyrinic complexes was carried out using microwave irradiation assisted synthesis. 
Methyl 4-formyl benzoate $(0.45 \mathrm{~mol})$, 3-hydroxybenzaldehyde $(0.15 \mathrm{~mol})$, fresh distilled pyrrole (0.60 mol), copper chloride anhydrous $(0.15 \mathrm{~mol}), 2,6$-dimethylpyridine $(1 \mathrm{~mL})$ and silicagel 60 (200-500 $\mu \mathrm{m}, 35-70$ mesh, $8 \mathrm{~g}$ ) dry silica were mixed at room temperature in a Pyrex bottle. 2,6Dimethylpyridine is a Lewis base and captures the hydrogen of the porphyrinic ring to produce the porphyrin dianion $\left(\mathrm{P}^{2-}\right)$, the copper ion $\left(\mathrm{Cu}^{2+}\right)$ is attracted by the $\mathrm{P}^{2-}$ to form the copper porphyrin. The mixture reaction was irradiated in a $475 \mathrm{~W}$ domestic microwave oven at $180{ }^{\circ} \mathrm{C}$ (final temperature), for 8 min. Extraction of samples for monitoring the synthesis was performed after every 2 min of irradiation. The presence of the complex in the reaction mixture was monitored by UV-Vis spectroscopy. The crude product was then purified on chromatography column by several elutions, using dichloromethane as eluent and silica gel (100-200 mesh size) as stationary phase; to obtain the final copper porphyrinic complexes, preparative TLC (on $2 \mathrm{~mm}$ silicagel 60 plates) was used. The same procedure was adopted in the preparation of 5,10,15,20-meso-tetrakis-(4-carboxymethylphenyl)21, $23 \mathrm{Cu}$ (II) porphine. The yields obtained were $68 \%$ for $\mathrm{Cu}(\mathrm{II}) \mathrm{TCMPOH}_{\mathrm{m}}$ and $83 \%$ for $\mathrm{Cu}(\mathrm{II}) \mathrm{TCMP}$, respectively. Following the preparation the copper porphyrins were characterized by IR, UV-VIS and EPR spectrometry.

To compare the two synthesis procedures, the synthesis of the copper porphyrin complexes was also carried following the method described in a previous paper [33]. Solutions $\left(\sim 10^{-4} \mathrm{M}\right)$ of the porphyrinic ligands TCMP and $\mathrm{TCMPOH}_{\mathrm{m}}$ [33] in dichloromethane were gently heated while stirred, until the ligand crystals were completely dissolved. Then, several drops of 2,6-dimethylpyridine were added, together with the appropriate amount of anhydrous $\mathrm{CuCl}_{2}$ in methanol solution, to yield the copper metal complexes in a 1:1 molar ratio. The reaction mixture was refluxed, under continuous stirring, for $1 \mathrm{~h}$, at $55^{\circ} \mathrm{C}$. The presence of the complex in the reaction mixture was monitored during the reaction by thin layer chromatography. After cooling, the reaction mixture was purified passing it through a silica gel chromatographic column. The solutions of the complexes in dichloromethane were concentrated by simple distillation. The violet crystals were dried at about $100{ }^{\circ} \mathrm{C}$, for $12 \mathrm{~h}$.

The physical-chemical data of copper porphyrins prepared via the two different methods described above are identical; in addition the reactions presented in this paper have been successfully repeated several times with the same results.

\section{Conclusions}

The paper presents the non-conventional synthesis of a new asymmetrical $\mathrm{Cu}$ (II) porphyrinic complex, 5-(3-hydroxyphenyl)-10,15,20-tris-(4-carboxymethylphenyl)-21,23 $\mathrm{Cu}$ (II) porphine and its corresponding symmetrical compound 5,10,15,20-meso-tetrakis(4-carboxymethylphenyl)-21,23 $\mathrm{Cu}$ (II) porphine, by means of microwave irradiation assisted solvent-free synthesis. The copper porphyrinic complexes were synthesized to be used as PDT sensitizers.

The spectral properties of the $\mathrm{Cu}(\mathrm{II})$ porphyrinic complexes were investigated by FTIR, EPR and UV-Vis spectroscopy. The influence of the solvent polarity on the molecular absorption band maxima was also described. A blue shift of the spectral bands was observed with increasing solvent polarity, determined by interactions between porphyrinic substituents and the solvent molecule.

Preliminary viability and proliferation in vitro tests were performed on MCF7 (human mammary carcinoma) and B16 (murine cutaneous melanoma) cell lines, for different doses and incubation times. 
The results of the biological in vitro tests indicated a low cytotoxicity of the compounds for the studied cells. The concentration ranges tested would give valuable information for further settling of a concentration for the compounds to be tested in view of PDT applications.

\section{Acknowledgements}

This work was supported by CNMP project No. 41-047/2007

\section{References and Notes}

1. Biesaga, M.; Pyrzyńska, K.; Trojanowicz, M. Porphyrins in analytical chemistry. A review. Talanta 2000, 51, 209-224.

2. Moan, J.; Peng, Q. An outline of history of PDT. In Photodynamic Therapy; Patrice, T., Ed.; Royal Society of Chemistry: Cambridge, UK, 2004; pp. 1-18.

3. Stockert, J.C.; Cañete, M.; Juarranz, A.; Villanueva, A.; Horobin, R.W.; Borrell, J.I.; Teixidó, J.; Nonell S. Porphycenes: Facts and Prospects in Photodynamic Therapy of Cancer. Curr. Med. Chem. 2007, 14, 997-1026.

4. Banfi, S.; Caruso, E.; Caprioli, S.; Mazzagatti, L.; Canti, G.; Ravizza, R.; Gariboldia, M.; Montia, E. Photodynamic effects of porphyrin and chlorin photosensitizers in human colon adenocarcinoma cells. Bioorg. Med. Chem. 2004, 12, 4853-4860.

5. Chen, J.Y.; Mak, N.K.; Yow, C.M.N.; Fung, M.C.; Chiu, L.C.; Leung, W.N.; Cheung, N.H. The Binding Characteristics and Intracellular Localization of Temoporfin (mTHPC) in Myeloid Leukemia Cells: Phototoxicity and Mitochondrial Damage. Photochem. Photobiol. 2000, 72, 541-547.

6. Detty, M.R.; Gibson, S.L.; Wagner, S.J. Current Clinical and Preclinical Photosensitizers for Use in Photodynamic Therapy. J. Med. Chem. 2004, 47, 3897-3195.

7. Grosseweiner, L.I. The Science of Phototherapy; CRC Press: London, UK, 1994; pp. 139.

8. Schweiter, C.; Schmidt, R. Physical Mechanisms of Generation and Deactivation of Singlet Oxygen. Chem. Rev. 2003, 103, 1685-1758.

9 Chatterjee, D.K.; Fong, L.S.; Zhang, Y. Nanoparticles in photodynamic therapy: An emerging paradigm. Adv. Drug Delivery Rev. 2008, 60, 1627-1637.

10. Mody, T.D.; Sessler, J.L. Porphyrin- and Expanded Porphyrin- based Diagnostic and Therapeutic Agents In Supramolecular Materials and Technologies; Reinhoud, D.N., Ed.; Wiley: Chichester, UK, 1999; Volume 4, p.126.

11. Kreimer-Birnbaum, M. Modified porphyrins, chlorins, phthalocyanines, and purpurins: secondgeneration photosensitizers for photodynamic therapy. Semin. Hematol. 1989, 26, 157-173.

12. Kostenich, G.; Orenstein, A.; Malik, Z.; Ehrenberg, B. Preclinical photodynamic therapy studies with endogenous and new exogenous photosensitizers. In Quantitative Data of 2nd and 3rd Generation Photosensitizers for Photodynamic Therapy; Moser, J.G., Ed.; Harwood Academic Publishers: Amsterdam, The Netherlands, 1998; pp. 101-114.

13. Ris, H.B.; Krueger, T.; Giger, A.; Lim, C.K; Stuart, J.C.M; Althaus, U.; Altermatt, H.J. Photodynamic therapy with mTHPC and polyethylene glycol-derived mTHPC: a comparative study on human tumour xenografts. Br. J. Cancer 1999, 79, 1061-1066. 
14. Bonnett, R. Chemical Aspects of Photodynamic Therapy (Advanced Chemistry Texts V.1); Gordon and Breach Science Publishers: Amsterdam, The Netherlands, 2000; pp. 57-112.

15. Postino, F.; Mora, M.; DeMadariaga, M.A.; Nonell, S.; Sagrista, M.L Incorporation of hydrophobic porphyrins into liposomes: characterization and structural requirements. Int. J. Pharma. 2004, 278, 239-254.

16. Scalise, I.; Durantini, E.N. Photodynamic effect of metallo 5-(4-carboxyphenyl)-10,15,20-tris(4methylphenyl) porphyrins in biomimetic AOT reverse micelles containing urease. J. Photochem. Photobiol. A 2004, 162, 105-113.

17. Boyle, R.B.; Dolphin, D. Structure and Biodistribution Relationships of Photodynamic Sensitizers. Photochem. Photobiol. 1996, 64, 469-485.

18. Mac Donald, I.J.; Dougherty, T.J. Basic principles of photodynamic therapy. J. Porphyrins Phthalocyanines 2001, 5, 105-129.

19. Nyman, E.S.; Hynninen, P.H. Research advances in the use of tetrapyrrolic photosensitizers for photodynamic therapy. J. Photochem. Photobiol. B 2004, 73, 1-28.

20. Ricchelli, F.; Jori, G.; Gobbo, S.; Tronchin, M. Liposomes as models to study the distribution of porphyrins in cell membranes. Biochim. Biophys. Acta 1991, 1065, 42-48.

21. J. Osterloh, M.G.H. Vicente, Mechanisms of porphyrinoid localization in tumors. J. Porphyrins Phthalocyanines 2002, 6, 305-325.

22. Milgrom, L.; MacRobert, S. Light years ahead. Chem. Br. 1998, 34, 45-50.

23. Socoteanu, R.; Boscencu, R.; Nacea, V.; Sousa Oliveira, A.; Vieira Ferreira, L.F. Microwaveassisted Synthesis of Unsymmetrical Tetrapyrrolic Compounds. Rev. Chim. 2008, 59, 969-972.

24. Boscencu, R.; Socoteanu, R.; Oliveira, A.S.; Vieira Ferreira, L.F.; Nacea, V.; Patrinoiu, G.; Synthesis and Characterization of Some Unsymmetrically-substituted Mesoporphyrinic MonoHydroxyphenyl Complexes of Copper(II). Pol. J. Chem. 2008, 82, 509-522.

25. Boscencu, R.; Socoteanu, R.; Oliveira, A.S.; Ferreira, L.F.V. Studies on Zn(II) monohydroxyphenyl mesoporphyrinic complexes. Synthesis and characterization. J. Serb. Chem. Soc. 2008, 73, 713-726.

26. Milgrom, L.R. The Colours of Life. An Introduction to the Chemistry of Porphyrins and Related Compounds; Oxford University Press: Oxford, UK, 1977; pp. 1-3.

27. Harriman, A. Luminescence of porphyrins and metalloporphyrins. Part 2. Copper(II), chromium(III), manganese(III), iron(II) and iron(III) porphyrins. J. Chem. Soc. Faraday Trans. 1981, 77, 369-377.

28. Reichardt, C.H. Solvents and Solvent Effects in Organic Chemistry; VCH: New York, NY, USA, 1988.

29. Lin, W.C. Electron Spin Resonance and Electronic Structure of Metalloporphyrins. In The Porphyrins; Dolphin, D., Ed.; Academic Press: New York, NY, USA, 1978; Volume 4, p. 358.

30. Manoharan, P.T.; Roger, M.T. Electron Spin Resonance of Metal Complexes; Yen, T.F., Ed.; Plenum Press: New York, NY, USA, 1969; pp. 143.

31. Kivelson, D.; Neiman, R.R. ESR Studies on the Bonding in Copper Complexes. J. Chem. Phys. 1961, 35, 149-155.

32. Korzeniewski, C.; Callewaert, D.M. An enzyme-release assay for natural cytotoxicity. J. Immunol. Meth. 1983, 64, 313-320. 
33. Barltrop, J.A.; Owen, T.C.; Cory, A.H.; Cory, J.G. 5-(3-carboxymethoxyphenyl)-2-(4,5dimethylthiazolyl)-3-(4-sulfophenyl)tetrazolium, inner salt (MTS) and related analogs of 3-(4,5dimethylthiazolyl)-2,5-diphenyltetrazolium bromide (MTT) reducing to purple water-soluble formazans as cell-viability indicators. Bioorg. Med. Chem. Lett. 1991, 1, 611-614.

34. Adam, D. Microwave chemistry: Out of the kitchen. Nature 2003, 421, 571-572.

35. Wei, T.H. Microwave-assisted synthesis and reverse saturable absorption of phthalocyanines and porphyrins. J. Organomet. Chem. 2004, 689, 1078-1084.

36. Liu, M.O.; Hu, A.T. Microwave-assisted synthesis of phthalocyanine-porphyrin complex and its photoelectric conversion properties. J. Organomet. Chem. 2004, 689, 2450-2455.

37. Boufatah, N.; Gellis, A.; Maldonado, J.; Vanelle, P. Efficient microwave-assisted synthesis of new sulfonylbenzimidazole-4,7-diones: heterocyclic quinones with potential antitumor activity. Tetrahedron 2004, 60, 9131-9137.

38. Sauer, D.R.; Kalvin, D.; Phelan, K.M. Microwave-Assisted Synthesis Utilizing Supported Reagents: A Rapid and Efficient Acylation Procedure. Org. Lett. 2003, 5, 4721-4724.

39. Yoon, D.S.; Han, Y.; Stark, T.M.; Haber, J.C.; Gregg, B.T.; Stankovich, S.B. Efficient Synthesis of 4-Aminoquinazoline and Thieno[3,2-d]pyrimidin-4-ylamine Derivatives by Microwave Irradiation. Org. Lett. 2004, 6, 4775-4778.

Sample Availability: Samples of the compounds are available from the authors.

(C) 2010 by the authors; licensee MDPI, Basel, Switzerland. This article is an Open Access article distributed under the terms and conditions of the Creative Commons Attribution license (http://creativecommons.org/licenses/by/3.0/). 